Escuela de Relaciones Internacionales.

Universidad Nacional, Costa Rica.

N. ${ }^{\circ} 89.1$ • Enero-Junio de 2016

doi: http://dx.doi.org/10.15359/ri.89-1.8

Pp. 171-190

\title{
ESFUERZOS LATINOAMERICANOS EN TORNO A LOS DERECHOS DEL CONSUMIDOR: CAN Y MERCOSUR*
}

\author{
Angélica María Reyes Sánchez** \\ Luisa Fernanda García Salazar***
}

\section{RESUMEN}

En un espacio sin fronteras, la cooperación y la construcción de identidades pueden lograrse a partir de la consolidación de esfuerzos comunes que permitan la protección de las relaciones jurídicas derivadas del comercio electrónico y, específicamente, de la parte débil en dicha relación: el consumidor. En este marco, las presentes líneas contienen algunos avances de un proyecto de investigación que busca analizar los esfuerzos jurídicos que han adelantado los países miembros y asociados de la Comunidad Andina de Naciones - CAN y el Mercado Común del Sur-MERCOSUR, en torno a la protección de los derechos del consumidor.

Palabras clave: Derechos del consumidor, CAN, MERCOSUR, identidad.

\section{ABSTRACT:}

In an area without borders [1], cooperation and construction of identities can be achieved by the consolidation of joint efforts in order to ensure the protection of legal relations arising from electronic commerce and, specifically, of the relationship between the weaker party and the consumer.

This article contains some advances of a research project that seeks to analyze the legal efforts of the members and associate countries of the Andean Community of Nations (CAN) [2] and the Southern Common Market (MERCOSUR) [3] for consumer rights protection.

Keywords: Consumer rights; CAN; MERCOSUR; identity

* Avance del proyecto de investigación "Fundamentos normativos de la mediación en línea de los conflictos derivados del comercio electrónico transfronterizo: Estudio del caso MERCOSUR y CAN" presentado en conjunto UPB - USTA aprobado en convocatoria interna de investigación 2014 y VIII, respectivamente.

** Magíster en Hermenéutica Jurídica y Derecho de la Universidad Industrial de Santander - Colombia, Estudios de Maestría en Derecho con énfasis en Derecho Empresarial y Contractual modalidad investigación y Abogado con título Cum Laude de la Universidad Santo Tomás Bucaramanga - Colombia. Investigador CIPJURIS, Universidad Pontificia Bolivariana - Bucaramanga. Correo electrónico: angelica.reyes@upb.edu.co

***Abogada Universidad Santo Tomas, Especialista en Negociación, Conciliación y Arbitraje, Magíster en Derecho de la Empresa de la Universidad de Navarra (España), Abogado Consultor en Resolución de Conflictos. Investigador CIPJURIS, Universidad Pontificia Bolivariana - Bucaramanga. Correo electrónico: luisa.garcias@upb.edu.co

****La Comunidad Andina de Naciones es una organización integrada con el objetivo de alcanzar un desarrollo integral, más equilibrado y autónomo, mediante la integración andina, suramericana y latinoamericana. Integrada por Bolivia, Colombia, Ecuador y Perú (CAN, s. f.).

*****El Mercado Común del Sur - MERCOSUR - está integrado por la República Árgentina, la República Federativa de Brasil, la República del Paraguay, la República Oriental del Uruguay, la República Bolivariana de Venezuela y el Estado Plurinacional de Bolivia, además de los países asociados. Los Estados Partes que conforman el MERCOSUR comparten una comunión de valores que encuentra expresión en sus sociedades democráticas, pluralistas, defensoras de las libertades fundamentales, de los derechos humanos y del desarrollo sustentable, así como su compromiso con el desarrollo económico y social con equidad (MERCOSUR, s. f.). 


\section{Integración latinoamericana}

La incorporación de textos constitucionales en los países latinoamericanos motivó la consideración de la integración como un propósito de Estado que se plasmó en dichas disposiciones normativas, con el fin de lograr la consolidación de relaciones armónicas en torno a objetivos comunes a las Naciones.

En este marco de integración, se han generado acuerdos de apoyo económico, político, social, ambiental, entre otros, que han justificado la necesidad de comunicación y trabajo conjunto de los países. De esta manera, surgen dos grupos o comunidades de reconocida gestión en Latinoamérica: la Comunidad Andina de Naciones - CAN y el Mercado Común del Sur - MERCOSUR.

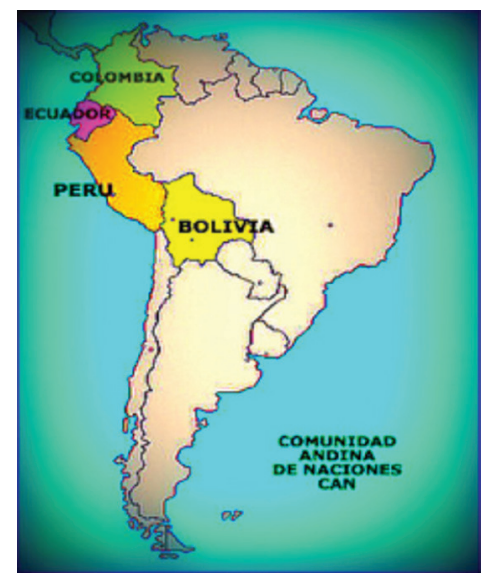

Figura 1. Países miembros de la CAN. (Comunidad Andina, s. f.).

La CAN, integrada por Bolivia, Colombia, Perú y Ecuador (figura 1), busca "promover el desarrollo armónico y equilibrado de sus Países Miembros, mediante la integración y la cooperación económica y social; así como, disminuir la vulnerabilidad externa y mejorar la posición de los Países Miembros en el contexto económico internacional" (CAN, 2002, p. 14), de allí que sus logros se enmarquen en temas de interés mundial como el mercado, los derechos de los ciudadanos, el desarrollo social, la salud, el medio ambiente, las telecomunicaciones, la integración con otros bloques económicos, entre otros. Para los efectos de la investigación que motiva las presentes líneas, resultan importantes los logros alcanzados respecto al mercado y los derechos de la ciudadanía, como escenarios que favorecen la consolidación de espacios de integración.

En este sentido, la CAN ha establecido recomendaciones tendientes a la materialización de sus propósitos, dentro de las cuales se destacan: 
- Ejecutar un plan integral para superar las dificultades y obstáculos que impiden el desarrollo del comercio electrónico.

- Exhortar a los países de la Comunidad Andina a que aproximen su legislación sobre la materia, para su posterior armonización, contribuyendo así al establecimiento del Mercado Común.

- Establecer los mecanismos e instrumentos jurídicos que brinden seguridad a las transacciones comerciales que se realizan por el medio digital.

- Lograr la consolidación del principio de equivalencia funcional del documento electrónico y firma electrónica en las leyes, para que puedan competir en igualdad de condiciones con los documentos tradicionalmente aceptados. (CAN, 2002, p. 14)

En virtud del cumplimiento de estas recomendaciones, los países miembros han logrado establecer privilegios a sus ciudadanos, que redundan en escenarios para la integración. Entre estos se destacan los logros en los derechos de los ciudadanos y en el mercado ampliado, como se ha mencionado con antelación.

En el marco de los derechos ciudadanos, los esfuerzos de integración son claros, pues todos los nacionales de los países miembros tienen los derechos y privilegios que se organizan en la figura 2.

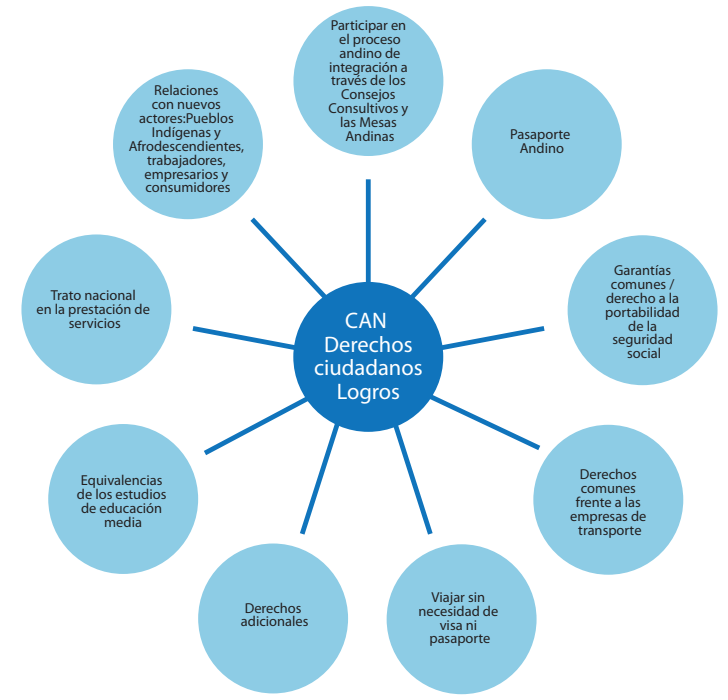

Figura 2. Logros de la CAN: Derechos de los ciudadanos. (Información obtenida de la CAN, s. f.). 
De esta manera, la CAN ha consolidado un espacio de integración que busca que sus países miembros respondan a las necesidades propias de su entorno, de manera armónica y colaborativa, lo que se ha traducido en la inclusión de elementos comunes que facilitan la vida y bienestar de sus ciudadanos.

El cumplimiento de las recomendaciones de armonización y colaboración, generadas por la CAN, y asumidas por los países miembros a partir de los logros descritos en la figura 2, se hace posible a partir de los ordenamientos jurídicos de los países miembros. Por ejemplo, Colombia establece, desde la Constitución Política, un marco "comprometido a impulsar la integración de la comunidad latinoamericana" (Asamblea Nacional Constituyente, 1991, Preámbulo). Por su parte, Ecuador se reconoce como "un país democrático, comprometido con la integración latinoamericana - sueño de Bolívar y Alfaro-, la paz y la solidaridad con todos los pueblos de la tierra" (Asamblea Constituyente, 2008, Preámbulo); mientras que Bolivia, en su deseo de buen vivir, se "reconoce comprometida con el desarrollo integral y con la libre determinación de los pueblos [así como] con la unidad e integridad del país" (Asamblea Constituyente, 2007, Preámbulo) [y se reconoce promotor de] "la cooperación entre los pueblos de la región y del mundo, a fin de contribuir al conocimiento mutuo, al desarrollo equitativo y a la promoción de la interculturalidad, con pleno respeto a la soberanía de los Estados" (Asamblea Constituyente, 2007, Art. 10). Finalmente Perú, en su Constitución Política, de manera más rigurosa, establece, como deber del Estado, "establecer y ejecutar la política de fronteras y promover la integración, particularmente latinoamericana, así como el desarrollo y la cohesión de las zonas fronterizas, en concordancia con la política exterior" (Congreso Constituyente Democrático, 2009, Art. 44).

Estos propósitos de integración, desarrollados por las diversas disposiciones normativas establecidas por la CAN e internamente por cada país miembro, permiten la cooperación y construcción de identidades comunitarias, en este caso andinas, que se traducen en logros para la región latinoamericana, entre ellos un mercado ampliado, como se verá más adelante.

En procura de materializar la cooperación y construcción de identidades, Latinoamérica cuenta con otro grupo de reconocido liderazgo: el Mercado Común del Sur - MERCOSUR.

En el Mercado Común del Sur, los países se encuentran organizados en miembros y asociados. En el grupo de países miembros se encuentran Argentina, Paraguay, Brasil, Uruguay y Venezuela en calidad de países miembros y en el de países asociados están Bolivia, Chile, Colombia, Ecuador y Perú (figura 3). 
MERCOSUR propone a los países que lo integran:

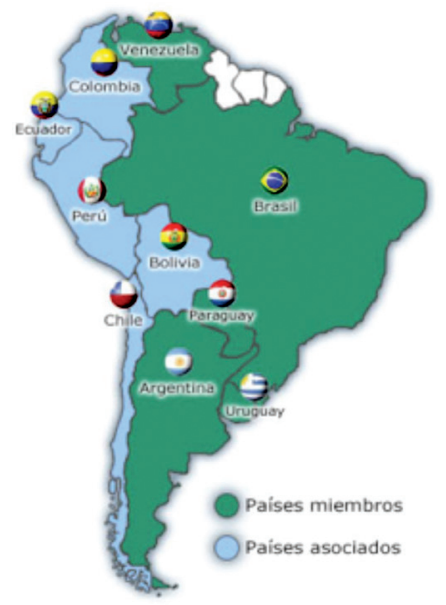

Figura 3. Países miembros de MERCOSUR. (MERCOSUR, s. f.).

a. La libre circulación de bienes, servicios y factores productivos entre los países, a través, entre otros, de la eliminación de los derechos aduaneros y restricciones no arancelarias a la circulación de mercaderías y de cualquier otra medida equivalente;

b. El establecimiento de un arancel externo común y la adopción de una política comercial común con relación a [sic] terceros Estados o agrupaciones de Estados y la coordinación de posiciones en foros económicos - comerciales regionales e internacionales;

c. La coordinación de políticas macroeconómicas y sectoriales entre los Estados Partes: de comercio exterior, agrícola, industrial, fiscal, monetaria, cambiaria y de capitales, de servicios, aduanera, de transportes y comunicaciones y otras que se acuerden, a fin de asegurar condiciones adecuadas de competencia entre los Estados Partes; y

d. el compromiso de los Estados Partes de armonizar sus legislaciones en las áreas pertinentes, para lograr el fortalecimiento del proceso de integración. (MERCOSUR, 1991, Art. 1)

La construcción de identidad es viable en los países que integran el MERCOSUR, a partir de los fundamentos normativos que cada uno de ellos ha establecido. Tanto los países asociados como los países miembros consagran la integración como propósito o deber de sus Estados, así lo resaltan los postulados 
constitucionales de integración ya descritos para Colombia, Ecuador, Bolivia y Perú.

Lo anterior se complementa con las disposiciones de la Constitución Política de la República de Chile que, en los mismos términos de Perú, impone al Estado el deber de "respetar y promover... los tratados internacionales ratificados por Chile y que se encuentren vigentes” (República de Chile, 2005, Art. 5). Así como lo establecido por la Constitución Política de la Nación Argentina, al advertir que corresponde al Congreso "Aprobar tratados de integración que deleguen competencia y jurisdicción a organizaciones supraestatales en condiciones de reciprocidad e igualdad, y que respeten el orden democrático y los derechos humanos" (Congreso General Constituyente, 1994, Art. 75, N. ${ }^{\circ}$ 24).

Lo propio hace la República Federal de Brasil al manifestar, abiertamente, que se "encuentra fundada en la armonía social y comprometida, en el orden interno e internacional, en la solución pacífica de sus controversias" (Asamblea Nacional Constituyente, 1988, Preámbulo) y al establecer un conjunto de principios ${ }^{1}$ que rigen sus relaciones internacionales. En el caso de la República Bolivariana de Venezuela, la Asamblea Nacional Constituyente (1999) fue establecida con el fin de refundar la República para establecer una sociedad que "promueve la cooperación pacífica entre las naciones e impulse y consolide la integración latinoamericana de acuerdo con el principio de no intervención y autodeterminación de los pueblos" (Preámbulo); mientras que Uruguay reconoce su lugar en la región, al establecer que la República "procurará la integración social y económica de los Estados Latinoamericanos, especialmente en lo que se refiere a la defensa común de sus productos y materias primas. Asimismo, propenderá a la efectiva complementación de sus servicios públicos" (República Oriental de Uruguay, 1997, Art. 6). Paraguay, por su parte, se define como un pueblo "integrado a la comunidad internacional" (Convención Nacional Constituyente, 1992, Preámbulo).

Son los postulados constitucionales descritos los que caracterizan el fundamento del marco normativo de los países latinoamericanos y los que permiten la cooperación y construcción de identidades comunitarias, como una posibilidad

1. Art. 4. La República Federativa de Brasil se rige en sus relaciones internacionales por los siguientes principios:

1. independencia nacional;

2. prevalencia de los derechos humanos;

3. autodeterminación de los pueblos;

4. no intervención;

5. igualdad de los Estados;

6. defensa de la paz;

7. solución pacífica de los conflictos;

8. repudio del terrorismo y del racismo;

9. cooperación entre los pueblos para el progreso de la humanidad;

10. concesión de asilo político. (Asamblea Nacional Constituyente, 1988, Preámbulo) 
de aunar esfuerzos en temas mucho más puntuales, como es la protección de los derechos del consumidor.

\section{Derechos del consumidor: Esfuerzos latinoamericanos}

La protección de los consumidores hace parte de la agenda de los países miembros de la CAN y el MERCOSUR, máxime cuando los propósitos de cooperación buscan la consolidación de un mercado aplicado o común que garantice a sus habitantes el desarrollo de sus dimensiones.

En torno a la protección de los derechos del consumidor, es necesario precisar que la CAN reconoce el avance y evolución del comercio electrónico y acepta la categorización elaborada por "The Economist Intelligence y el ebussiness Forum, en cuatro grupos, dentro del cual se encuentran los seguidores ( $f o l$ lowers) del $e$-bussines" (CAN, 2002, p. 13); mientras que el MERCOSUR, a través del Proyecto MERCOSUR Digital, ha identificado los problemas típicos que enfrenta un consumidor en internet.

Dentro de los problemas que enfrentan los consumidores en internet, se destacan los siguientes:

- La falta de diversidad en los medios de pago.

- El encarecimiento de los costos impositivo/aduaneros y de logística para los productos físicos.

- La falta de percepción de seguridad y la falta de confianza que experimentan los consumidores ante un problema con una empresa extranjera por desconocimiento de la legislación aplicable o la jurisdicción competente (o ambos).

- La inexistencia de mecanismos alternativos de solución de controversias en línea.

- La calidad, cantidad y características de los productos o servicios contratados, así como el cumplimiento de los tiempos de entrega.

- Problemas de idioma cuando se trata de sitios de lengua extranjera. 
- Inexistencia de comparadores de precios a nivel transfronterizo.

- Desconocimiento de marcas cuando se trata de Pymes.

- Dudas respecto de los procedimientos y normativa aduanera aplicable.

En el marco del objetivo de la CAN, establecida para "promover el desarrollo armónico y equilibrado de sus Países Miembros, mediante la integración y la cooperación económica y social; así como, disminuir la vulnerabilidad externa y mejorar la posición de los Países Miembros en el contexto económico internacional" (CAN, 2002, p. 14), el comercio electrónico ha sido objeto de múltiples debates y reuniones $\mathrm{y}$, en virtud de este mismo, se han establecido recomendaciones como:

- Ejecutar un plan integral para superar las dificultades y obstáculos que impiden el desarrollo del comercio electrónico.

- Exhortar a los países de la Comunidad Andina a que aproximen su legislación sobre la materia, para su posterior armonización, contribuyendo así al establecimiento del Mercado Común.

- Evaluar todos y cada uno de los cuerpos jurídicos de cada país para evitar contradicciones o posteriores acciones en contra de las Leyes Marco que se implementen.

- Establecer los mecanismos e instrumentos jurídicos que brinden seguridad a las transacciones comerciales que se realizan por el medio digital.

- Lograr la consolidación del principio de equivalencia funcional del documento electrónico y firma electrónica en las leyes, para que puedan competir en igualdad de condiciones con los documentos tradicionalmente aceptados. (CAN, 2002, p. 14)

A partir de estas recomendaciones, la CAN realiza un diagnóstico de la legislación de sus países miembros a fin de establecer directrices que posibiliten la armonización a través de una directriz comunitaria ${ }^{2}$. Los temas de regulación analizados giran en torno a mensajes de datos, firma electrónica, certificados digitales, entidades / autoridades de certificación y registro. Deja, para un segundo reporte, el análisis de los demás temas, dentro de los cuales es imperati-

2 El diagnóstico y las recomendaciones de la CAN pueden consultarse en CAN, 2002, Legislación sobre Comercio Electrónico en los países miembros de la comunidad Andina. Análisis comparativo, recomendaciones para su armonización. Con apoyo de Unión Internacional de Telecomunicaciones. 
vo que se involucre el del consumidor, sus derechos y sus posibilidades de protección, especialmente frente al proveedor ubicado fuera del territorio nacional.

El análisis propiciado por la CAN reconoce los avances que en tema de comercio electrónico han desarrollado la Comunidad Económica Europea y las Naciones Unidas a través de la Comisión de las Naciones Unidas para el Derecho Mercantil Internacional (CNUDMI), por lo que resulta pertinente revisar lo previsto por esta comisión.

Por su parte, MERCOSUR reconoce que las tecnologías de la información y la comunicación son un elemento que apalanca la evolución del comercio y los negocios electrónicos, haciendo posible el funcionamiento de la economía global; sin embargo, impone una reingeniería en las formas de relación de los agentes que intervienen en el mercado y, en consecuencia, de los insumos de regulación que se han establecido para su adecuado desarrollo, entre ellas el uso de tecnologías de información y comunicación (TIC), pues no cabe duda de que contribuye al desarrollo de la gestión empresarial contemporánea (REMOLINA, 2006).

Las dificultades identificadas deben ser resueltas de manera armónica, si Latinoamérica desea contribuir con el desarrollo de sus pueblos y, ¿qué mejor manera que aprovechar los propósitos de integración, materializados a través de la CAN y el MERCOSUR, para lograr este propósito?, ¿por qué no identificar las coincidencias normativas en cuanto a protección de los consumidores se refiere?, antes de adentrarnos en el $e$-commerce, tema que será objeto de futuros avances o resultados del proyecto. Es, a esta necesidad de estudios en torno a normatividades con elementos comunes que responde el presente acápite.

Los postulados constitucionales y legales de los países miembros de la CAN y MERCOSUR, que apuntan a proteger el desarrollo empresarial, el equilibrio del mercado y los derechos de los consumidores, se han identificado a través de tres principios que les dan fundamento, a saber: Libertad de empresa, iniciativa privada y libre competencia económica. Estos tres principios responden, de manera directa o indirecta, a las necesidades de protección de los consumidores, como eslabón débil de la cadena de distribución, de allí que sean las variables del análisis normativo realizado.

Atendiendo a estas tres premisas, los resultados se presentan de manera armónica, aprovechando los bloques de integración objeto de estudio: CAN y MERCOSUR.

Los países miembros de la CAN han establecido postulados constitucionales que otorgan a los ciudadanos facultades para desarrollar, de manera 
libre, cualquier actividad económica lícita, sin desconocer derechos y deberes derivados de dicha facultad, siempre desde premisas de protección. Así se pueden organizar los esfuerzos de protección a partir de un marco jurídico y económico que responde a las particularidades del mercado, según se desprende del siguiente normograma (Ver tabla 1).

El normograma que se presenta parte de un concepto común que identifica al sujeto de protección, esto es, el consumidor. Seguido de una representación gráfica que puede leerse así: $\mathrm{C}=(\mathrm{Epd}+\mathrm{Em}+\mathrm{Cons}) / \mathrm{ME}$, en donde $\mathrm{C}$ es Comercio electrónico, Epd es empresario productor o distribuido, Em es empresa, Cons es consumidor y ME es medios electrónicos. De esta representación gráfica se lee que la relación de consumo que deriva en comercio electrónico (C), surge de la relación de dos partes: el empresario productor o distribuidor (Epd) en un extremo, y en el otro, un destinatario final, denominado consumidor (Cons). La relación entre empresario y consumidor se justifica en el desarrollo de una actividad económica o empresa $(\mathrm{Em})$ que se desarrolla a través de medios electrónicos (ME).

Finalmente, en el normograma se encuentran cinco columnas contentivas de la información identificada del estudio de los ordenamientos jurídicos de los países miembros de la CAN y MERCOSUR. La primera columna indica la comunidad económica a la que se hace referencia, en la segunda el país que la integra, en la tercera lo referente a la libertad de empresa, en la cuarta los postulados en torno a iniciativa privada y en la quinta lo consagrado a libre competencia; estos últimos tres elementos, como instituciones jurídicas que posibilitan la relación de consumo (Ver tabla 1). 


\section{Tabla 1.}

\section{Normograma: CAN y MERCOSUR - Derechos del consumidor}

\begin{tabular}{|c|c|c|c|c|}
\hline \multicolumn{5}{|c|}{$\begin{array}{l}\text { Desarrollos normativos latinoamericanos, en torno a la protección de los derechos del consumidor como } \\
\text { escenario de integración y construcción de identidad comunitaria }\end{array}$} \\
\hline \multicolumn{5}{|c|}{ Consumidor } \\
\hline \multicolumn{5}{|c|}{$\begin{array}{l}\text { Toda persona natural o jurídica que, como destinatario final, adquiera, disfrute o utilice un determinado producto, cualquiera que } \\
\text { sea su naturaleza, para la satisfacción de una necesidad propia, privada, familiar o doméstica y empresarial cuando no esté ligada } \\
\text { intrínsecamente a su actividad económica. Se entenderá incluido en el concepto de consumidor el de usuario. } \\
\text { (REPÚBLICA DE COLOMBIA, 2011, ART. 49) }\end{array}$} \\
\hline \multicolumn{5}{|c|}{ Empresario (productor o distribuidor) - EMPRESA - Consumidor } \\
\hline \multicolumn{5}{|c|}{ Medios electrónicos } \\
\hline Comunidad & País & Libertad empresa & Iniciativa privada & Libre competencia \\
\hline \multirow[t]{3}{*}{$\begin{array}{l}\text { CAN } \\
\text { MERCOSUR }\end{array}$} & $\begin{array}{l}\text { Colombia } \\
\text { (Asamblea } \\
\text { Nacional } \\
\text { Constituyente, } \\
\text { 1991, Art. } \\
\text { 333). }\end{array}$ & $\begin{array}{l}\text { Ejercicio libre de cualquier } \\
\text { actividad económica. }\end{array}$ & $\begin{array}{l}\text { Conformación libre de } \\
\text { empresa sin permisos ni } \\
\text { requisitos previos, sin } \\
\text { autorización de libre. } \\
\text { Estado estimulará desarro- } \\
\text { llo empresarial. }\end{array}$ & Derecho de todos. \\
\hline & \multirow[t]{2}{*}{$\begin{array}{l}\text { Ecuador } \\
\text { (Asamblea } \\
\text { Constituyente, } \\
\text { 2008, Art. 52, } \\
66,335,336)\end{array}$} & $\begin{array}{l}\text { El derecho a asociarse, reu- } \\
\text { nirse y manifestarse en forma } \\
\text { libre y voluntaria. } \\
\text { El derecho a desarrollar } \\
\text { actividades económicas, en } \\
\text { forma individual o colectiva, } \\
\text { conforme a los principios de } \\
\text { solidaridad, responsabilidad } \\
\text { social y ambiental. }\end{array}$ & $\begin{array}{l}\text { El Estado regulará, contro- } \\
\text { lará e intervendrá, cuando } \\
\text { sea necesario, en los inter- } \\
\text { cambios y transacciones } \\
\text { económicas; y sancionará } \\
\text { la explotación, usura, } \\
\text { acaparamiento, simulación, } \\
\text { intermediación especulati- } \\
\text { va de los bienes y servicios, } \\
\text { así como toda forma de } \\
\text { perjuicio a los derechos } \\
\text { económicos y a los bienes } \\
\text { públicos y colectivos. }\end{array}$ & $\begin{array}{l}\text { El Estado definirá una } \\
\text { política de precios orientada } \\
\text { a proteger la producción } \\
\text { nacional, establecerá los } \\
\text { mecanismos de sanción para } \\
\text { evitar cualquier práctica } \\
\text { de monopolio y oligopolio } \\
\text { privados, o de abuso de } \\
\text { posición de dominio en el } \\
\text { mercado y otras prácticas de } \\
\text { competencia desleal. } \\
\text { EI Estado impulsará y velará } \\
\text { por el comercio justo como } \\
\text { medio de acceso a bienes y } \\
\text { servicios de calidad, que mi- } \\
\text { nimice las distorsiones de la } \\
\text { intermediación y promueva } \\
\text { la sustentabilidad. El Estado } \\
\text { asegurará la transparencia } \\
\text { y eficiencia en los mercados } \\
\text { y fomentará la competencia } \\
\text { en igualdad de condiciones } \\
\text { y oportunidades, lo que } \\
\text { se definirá mediante ley. } \\
\text { (Constitución Política de } \\
\text { Ecuador 2008). }\end{array}$ \\
\hline & & \multicolumn{3}{|c|}{$\begin{array}{l}\text { Las personas tienen derecho a disponer de bienes y servicios de óptima calidad y a elegirlos } \\
\text { con libertad, así como a una información precisa y no engañosa sobre su contenido y } \\
\text { características. La ley establecerá los mecanismos de control de calidad y los procedimientos } \\
\text { de defensa de las consumidoras y consumidores; y las sanciones por vulneración de estos } \\
\text { derechos, la reparación e indemnización por deficiencias, daños o mala calidad de bienes y } \\
\text { servicios, y por la interrupción de los servicios públicos que no fuera ocasionada por caso } \\
\text { fortuito o fuerza mayor. }\end{array}$} \\
\hline
\end{tabular}




\begin{tabular}{|c|c|c|c|c|}
\hline \multirow[t]{2}{*}{$\begin{array}{l}\text { CAN } \\
\text { MERCOSUR }\end{array}$} & \multirow[t]{2}{*}{$\begin{array}{l}\text { Perú } \\
\text { (Congreso } \\
\text { Constituyente } \\
\text { Democrático, } \\
\text { 2009, Art. 59, } \\
\text { 61,65). }\end{array}$} & $\begin{array}{l}\text { El Estado garantiza la liber- } \\
\text { tad de empresa, comercio e } \\
\text { industria. }\end{array}$ & $\begin{array}{l}\text { El Estado estimula la crea- } \\
\text { ción de riqueza y garantiza } \\
\text { la libertad de trabajo El } \\
\text { estado brinda oportuni- } \\
\text { dades de superación a } \\
\text { los sectores que sufren } \\
\text { cualquier desigualdad; en } \\
\text { tal sentido, promueve las } \\
\text { pequeñas empresas en todas } \\
\text { sus modalidades }\end{array}$ & $\begin{array}{l}\text { El Estado facilita y vigila la } \\
\text { libre competencia. Combate } \\
\text { toda práctica que la limite } \\
\text { y el abuso de posiciones } \\
\text { dominantes o monopólicas. } \\
\text { Ninguna ley ni concertación } \\
\text { puede autorizar ni establecer } \\
\text { monopolios. La prensa, la } \\
\text { radio, la televisión y los } \\
\text { demás medios de expresión } \\
\text { y comunicación social; y, } \\
\text { en general, las empresas, } \\
\text { los bienes y servicios rela- } \\
\text { cionados con la libertad de } \\
\text { expresión y de comunica- } \\
\text { ción, no pueden ser objeto } \\
\text { de exclusividad, monopolio } \\
\text { ni acaparamiento, directa } \\
\text { ni indirectamente, por parte } \\
\text { del Estado ni de particulares } \\
\text { (Constitución Política } \\
\text { Peruana de 1993). }\end{array}$ \\
\hline & & \multicolumn{3}{|c|}{$\begin{array}{l}\text { El Estado defiende el interés de los consumidores y usuarios. Para tal efecto garantiza el } \\
\text { derecho a la información sobre los bienes y servicios que se encuentran a su disposición en el } \\
\text { mercado. Asimismo vela, en particular, por la salud y la seguridad de la población" [Negrita } \\
\text { añadida] (Constitución Política Peruana de 1993). }\end{array}$} \\
\hline \multirow[t]{4}{*}{$\begin{array}{l}\text { CAN } \\
\text { MERCOSUR }\end{array}$} & \multirow[t]{2}{*}{$\begin{array}{l}\text { Bolivia } \\
\text { (Asamblea } \\
\text { Constituyente, } \\
\text { 2007, Art. 47, } \\
5275) \text {. }\end{array}$} & $\begin{array}{l}\text { Toda persona tiene derecho } \\
\text { a dedicarse al comercio, la } \\
\text { industria o a cualquier activi- } \\
\text { dad económica lícita. }\end{array}$ & $\begin{array}{l}\text { Se reconoce y garantiza el } \\
\text { derecho a la libre asocia- } \\
\text { ción empresarial. }\end{array}$ & $\begin{array}{l}\text { Toda persona tiene derecho } \\
\text { a dedicarse al comercio, } \\
\text { la industria o a cualquier } \\
\text { actividad económica lícita, } \\
\text { en condiciones que no perju- } \\
\text { diquen al bien colectivo. }\end{array}$ \\
\hline & & \multicolumn{3}{|c|}{$\begin{array}{l}\text { Las usuarias y los usuarios y las consumidoras y los consumidores gozan de los siguientes } \\
\text { derechos: } 1 \text {. Al suministro de alimentos, fármacos y productos en general, en condiciones de } \\
\text { inocuidad, calidad, y cantidad disponible adecuada y suficiente, con prestación eficiente y } \\
\text { oportuna del suministro. 2. A la información fidedigna sobre las características y contenidos } \\
\text { de los productos que consuman y servicios que utilicen. }\end{array}$} \\
\hline & \multirow[t]{2}{*}{$\begin{array}{l}\text { Argentina } \\
\text { (Congreso } \\
\text { General } \\
\text { Constituyente, } \\
\text { 1994, Art. } \\
14,42 \text { ) }\end{array}$} & $\begin{array}{l}\text { No registra fundamento } \\
\text { constitucional. }\end{array}$ & $\begin{array}{l}\text { No registra fundamento } \\
\text { constitucional. }\end{array}$ & $\begin{array}{l}\text { Defensa de la competen- } \\
\text { cia contra toda forma de } \\
\text { distorsión de los mercados, } \\
\text { al control de los monopolios } \\
\text { naturales y legales. }\end{array}$ \\
\hline & & \multicolumn{3}{|c|}{$\begin{array}{l}\text { Los consumidores y usuarios de bienes y servicios tienen derecho, en la relación de consumo, } \\
\text { a la protección de su salud, seguridad e intereses económicos; a una información adecuada y } \\
\text { veraz; a la libertad de elección, y a condiciones de trato equitativo y digno. Las autoridades } \\
\text { proveerán a la protección de esos derechos, a la educación para el consumo, al de la calidad } \\
\text { y eficiencia de los servicios públicos, y a la constitución de asociaciones de consumidores y } \\
\text { de usuarios. }\end{array}$} \\
\hline
\end{tabular}




\begin{tabular}{|c|c|c|c|c|}
\hline $\begin{array}{l}\text { CAN } \\
\text { MERCOSUR }\end{array}$ & $\begin{array}{l}\text { Venezuela } \\
\text { (Asamblea } \\
\text { Nacional } \\
\text { Constituyente, } \\
\text { 1999, Art. 87, } \\
113,117 \text { ) }\end{array}$ & $\begin{array}{l}\text { Todas las personas pueden } \\
\text { dedicarse libremente a la } \\
\text { actividad económica de } \\
\text { su preferencia, sin más } \\
\text { limitaciones que las previstas } \\
\text { en esta Constitución y las } \\
\text { que establezcan las leyes, } \\
\text { por razones de desarrollo } \\
\text { humano, seguridad, sanidad, } \\
\text { protección del ambiente u } \\
\text { otras de interés social. }\end{array}$ & $\begin{array}{l}\text { El Estado promoverá la } \\
\text { iniciativa privada, garanti- } \\
\text { zando la creación y } \\
\text { justa distribución de } \\
\text { la riqueza, así como la } \\
\text { producción de bienes y } \\
\text { servicios que satisfagan } \\
\text { las necesidades de la } \\
\text { población, la libertad de } \\
\text { trabajo, empresa, comercio, } \\
\text { industria, sin perjuicio } \\
\text { de su facultad para dictar } \\
\text { medidas para planificar, } \\
\text { racionalizar y regular la } \\
\text { economía e impulsar el } \\
\text { desarrollo integral del país. }\end{array}$ & $\begin{array}{l}\text { No se permitirán monopo- } \\
\text { lios. Se declaran contrarios a } \\
\text { los principios fundamen- } \\
\text { tales de esta Constitución } \\
\text { cualesquier acto, actividad, } \\
\text { conducta o acuerdo de los y } \\
\text { las particulares que tengan } \\
\text { por objeto el establecimiento } \\
\text { de un monopolio o que } \\
\text { conduzcan, por sus efectos } \\
\text { reales e independientemente } \\
\text { de la voluntad de aquellos } \\
\text { o aquellas, a su existencia, } \\
\text { cualquiera que fuere la } \\
\text { forma que adoptare en } \\
\text { la realidad. También es } \\
\text { contrario a dichos principios } \\
\text { el abuso de la posición de } \\
\text { dominio que un o una par- } \\
\text { ticular, un conjunto de ellos } \\
\text { o de ellas, o una empresa } \\
\text { o conjunto de empresas, } \\
\text { adquiera o haya adquirido } \\
\text { en un determinado mercado } \\
\text { de bienes o de servicios, con } \\
\text { independencia de la causa } \\
\text { determinante de tal posición } \\
\text { de dominio, así como cuan- } \\
\text { do se trate de una demanda } \\
\text { concentrada. En todos los } \\
\text { casos antes indicados, el } \\
\text { Estado adoptará las medidas } \\
\text { que fueren necesarias para } \\
\text { evitar los efectos nocivos y } \\
\text { restrictivos del monopolio, } \\
\text { del abuso de la posición de } \\
\text { dominio y de las demandas } \\
\text { concentradas. }\end{array}$ \\
\hline & & \multicolumn{3}{|c|}{$\begin{array}{l}\text { Protección del público consumidor, de los productores y productoras y el aseguramiento de } \\
\text { condiciones efectivas de competencia en la economía. Cuando se trate de explotación de re- } \\
\text { cursos naturales propiedad de la Nación o de la prestación de servicios de naturaleza pública } \\
\text { con exclusividad o sin ella, el Estado podrá otorgar concesiones por tiempo determinado, } \\
\text { asegurando siempre la existencia de contraprestaciones o contrapartidas adecuadas al interés } \\
\text { público. } \\
\text { Todas las personas tendrán derecho a disponer de bienes y servicios de calidad, así como a } \\
\text { una información adecuada y no engañosa sobre el contenido y características de los produc- } \\
\text { tos y servicios que consumen, a la libertad de elección y a un trato equitativo y digno. } \\
\text { La ley establecerá los mecanismos necesarios para garantizar esos derechos, las normas de } \\
\text { control de calidad y cantidad de bienes y servicios, los procedimientos de defensa del público } \\
\text { consumidor, el resarcimiento de los daños ocasionados y las sanciones correspondientes por } \\
\text { la violación de estos derechos. }\end{array}$} \\
\hline
\end{tabular}




\begin{tabular}{|c|c|c|c|c|}
\hline $\begin{array}{l}\text { CAN } \\
\text { MERCOSUR }\end{array}$ & 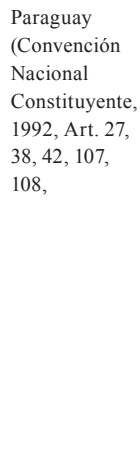 & $\begin{array}{l}\text { Toda persona tiene derecho a } \\
\text { dedicarse a la actividad eco- } \\
\text { nómica lícita de su preferen- } \\
\text { cia, dentro de un régimen de } \\
\text { igualdad de oportunidades. }\end{array}$ & $\begin{array}{l}\text { Toda persona es libre de } \\
\text { asociarse o agremiarse con } \\
\text { fines lícitos, así como nadie } \\
\text { está obligado a pertenecer a } \\
\text { determinada asociación. La } \\
\text { forma de colegiación pro- } \\
\text { fesional será reglamentada } \\
\text { por ley. Están prohibidas las } \\
\text { asociaciones secretas y las } \\
\text { de carácter paramilitar. }\end{array}$ & $\begin{array}{l}\text { Se garantiza la competencia } \\
\text { en el mercado. No serán per- } \\
\text { mitidas la creación de mo- } \\
\text { nopolios y el alza o la baja } \\
\text { artificiales de precios que } \\
\text { traben la libre concurrencia. } \\
\text { La usura y el comercio no } \\
\text { autorizado de artículos } \\
\text { nocivos serán sancionados } \\
\text { por la Ley Penal. } \\
\text { Los bienes de producción o } \\
\text { fabricación nacional, y los } \\
\text { de procedencia extranjera } \\
\text { introducidos legalmente, } \\
\text { circularán libremente } \\
\text { dentro del territorio de la } \\
\text { República. }\end{array}$ \\
\hline & & \multicolumn{3}{|c|}{$\begin{array}{l}\text { Los bienes de producción o fabricación nacional, y los de procedencia extranjera introduci- } \\
\text { dos legalmente, circularán libremente dentro del territorio de la República. } \\
\text { La ley regulará la publicidad a los efectos de la mejor protección de los derechos del niño, del } \\
\text { joven, del analfabeto, del consumidor y de la mujer. } \\
\text { Toda persona tiene derecho, individual o colectivamente, a reclamar a las autoridades } \\
\text { públicas medidas para la defensa del ambiente, de la integridad del hábitat, de la salubridad } \\
\text { pública, del acervo cultural nacional, de los intereses del consumidor y de otros que, por su } \\
\text { naturaleza jurídica, pertenezcan a la comunidad y hagan relación con la calidad de vida y con } \\
\text { el patrimonio colectivo. } \\
\text { La ley regulará la publicidad a los efectos de la mejor protección de los derechos del niño, del } \\
\text { joven, del analfabeto, del consumidor y de la mujer. }\end{array}$} \\
\hline
\end{tabular}




\begin{tabular}{|c|c|c|c|c|}
\hline $\begin{array}{l}\text { CAN } \\
\text { MERCOSUR }\end{array}$ & $\begin{array}{l}\text { Uruguay } \\
\text { (República } \\
\text { Oriental de } \\
\text { Uruguay, } \\
\text { 1997, Art. 2, } \\
36,39 \text { ) }\end{array}$ & $\begin{array}{l}\text { Cada persona puede } \\
\text { participar en el trabajo, la } \\
\text { agricultura, industria, co- } \\
\text { mercio, profesión o cualquier } \\
\text { otra actividad lícita, salvo las } \\
\text { limitaciones impuestas por } \\
\text { el interés general que la ley } \\
\text { pueda promulgar. }\end{array}$ & $\begin{array}{l}\text { Todas las personas tienen } \\
\text { el derecho a formar aso- } \\
\text { ciaciones, para cualquier } \\
\text { propósito, siempre que no } \\
\text { constituyan una asociación } \\
\text { que la ley ha declarado } \\
\text { ilegal. }\end{array}$ & $\begin{array}{l}\text { Todos los mercados estarán } \\
\text { regidos por los principios y } \\
\text { reglas de la libre competen- } \\
\text { cia, excepto las limitaciones } \\
\text { establecidas por ley, por } \\
\text { razones de interés general. } \\
\text { Se prohíbe el abuso de } \\
\text { posición dominante, así } \\
\text { como todas las prácticas, } \\
\text { conductas o recomendacio- } \\
\text { nes, individuales o concer- } \\
\text { tadas, que tengan por efecto } \\
\text { u objeto, restringir, limitar, } \\
\text { obstaculizar, distorsionar o } \\
\text { impedir la competencia ac- } \\
\text { tual o futura en el mercado } \\
\text { relevante. } \\
\text { A efectos de valorar las } \\
\text { prácticas, conductas o } \\
\text { recomendaciones indicadas } \\
\text { en el párrafo que antecede, } \\
\text { el órgano de aplicación } \\
\text { podrá tomar en cuenta si } \\
\text { esas prácticas, conductas o } \\
\text { recomendaciones generan } \\
\text { ganancias de eficiencia } \\
\text { económica de los sujetos, } \\
\text { unidades económicas y } \\
\text { empresas involucradas, la } \\
\text { posibilidad de obtener las } \\
\text { mismas a través de formas } \\
\text { alternativas, y el beneficio } \\
\text { que se traslada a los } \\
\text { consumidores. La conquista } \\
\text { del mercado resultante del } \\
\text { proceso natural fundado } \\
\text { en la mayor eficiencia del } \\
\text { agente económico en rela- } \\
\text { ción con sus competidores, } \\
\text { no constituye una conducta } \\
\text { de restricción de la com- } \\
\text { petencia. } \\
\text { El ejercicio de un derecho, } \\
\text { facultad o prerrogativa } \\
\text { excepcional otorgada o } \\
\text { reconocida por ley no } \\
\text { se considerará práctica } \\
\text { anticompetitiva ni abuso de } \\
\text { posición dominante. }\end{array}$ \\
\hline & & \multicolumn{3}{|c|}{$\begin{array}{l}\text { Ley } 17.250 \text {, específicamente el artículo } 6^{\circ} \text { reconoce como derechos básicos, entre otros: A) } \\
\text { La protección de la vida, la salud y la seguridad contra los riesgos causados por las prácticas } \\
\text { en el suministro de productos y servicios considerados peligrosos o nocivos; B) La educación } \\
\text { y divulgación sobre el consumo adecuado de los productos y servicios, la libertad de elegir } \\
\text { y el tratamiento igualitario cuando contrate; C) La información suficiente, clara, veraz, en } \\
\text { idioma español sin perjuicio que puedan emplearse además otros idiomas; D) La protección } \\
\text { contra la publicidad engañosa, los métodos coercitivos o desleales en el suministro de } \\
\text { productos y servicios y cláusulas abusivas en los contratos de adhesión, cada uno de ellos } \\
\text { dentro de los términos dispuestos en la presente ley; E) La asociación en organizaciones cuyo } \\
\text { objeto específico sea la defensa del consumidor y ser representado por ellas; F) La efectiva } \\
\text { prevención y resarcimiento de los daños patrimoniales y extra patrimoniales; G) El acceso a } \\
\text { organismos judiciales y administrativos para la prevención y resarcimiento de daños median- } \\
\text { te procedimientos ágiles y eficaces. }\end{array}$} \\
\hline
\end{tabular}




\begin{tabular}{|c|c|c|c|c|}
\hline \multirow[t]{2}{*}{$\begin{array}{l}\text { CAN } \\
\text { MERCOSUR }\end{array}$} & \multirow[t]{2}{*}{$\begin{array}{l}\text { Brasil } \\
\text { (Asamblea } \\
\text { Nacional } \\
\text { Constituyente, } \\
1988 \text {, Art. } 1 \text {, } \\
5,24,73,150, \\
170)\end{array}$} & $\begin{array}{l}\text { Excepto en los casos previs- } \\
\text { tos en esta Constitución, la } \\
\text { explotación directa de la ac- } \\
\text { tividad económica del Estado } \\
\text { solo se autorizará cuando sea } \\
\text { necesaria a los imperativos de } \\
\text { seguridad nacional o el rele- } \\
\text { vante interés colectivo, según } \\
\text { lo definido por la ley. }\end{array}$ & $\begin{array}{l}\text { Los valores sociales del } \\
\text { trabajo y la libre iniciativa. } \\
\text { El orden económico, } \\
\text { fundado en la valoración } \\
\text { del trabajo humano y en la } \\
\text { libre iniciativa, tiene por } \\
\text { fin asegurar a todos una } \\
\text { existencia digna, de acuer- } \\
\text { do con los dictados de la } \\
\text { Justicia Social, observando } \\
\text { los siguientes principios: } \\
\text { Tratamiento favorable para } \\
\text { las empresas brasileñas de } \\
\text { capital nacional de pequeño } \\
\text { porte. } \\
\text { El orden económico, } \\
\text { fundado en la valoración } \\
\text { del trabajo humano y en } \\
\text { la libre iniciativa, tiene } \\
\text { por fin asegurar a todos } \\
\text { una existencia digna, de } \\
\text { acuerdo con los dictados de } \\
\text { la Justicia Social. }\end{array}$ & $\begin{array}{l}\text { La ley reprimirá el abuso del } \\
\text { poder económico destinado } \\
\text { a la dominación de los mer- } \\
\text { cados, la eliminación de la } \\
\text { competencia y el aumento } \\
\text { arbitrario de los beneficios. } \\
\text { (Centro de Libre Competen- } \\
\text { cia, s, f. p. 1). }\end{array}$ \\
\hline & & \multicolumn{3}{|c|}{$\begin{array}{l}\text { El Estado promoverá, en la forma de la ley, la defensa del consumidor. } \\
\text { Responsabilidad por daños al medio ambiente, al consumidor, a los bienes y derechos de } \\
\text { valor artístico, estético, histórico, turístico y paisajístico. } \\
\text { La ley establecerá medidas para que los consumidores sean informados acerca de los impues- } \\
\text { tos que incidan en mercancías y servicios. } \\
\text { El orden económico, fundado en la valoración del trabajo humano y en la libre iniciativa, } \\
\text { tiene por fin asegurar a todos una existencia digna, de acuerdo con los dictados de la Justicia } \\
\text { Social, observando los siguientes principios: } 5 \text {. defensa del consumidor. }\end{array}$} \\
\hline $\begin{array}{l}\text { CAN } \\
\text { MERCOSUR }\end{array}$ & $\begin{array}{l}\text { Chile } \\
\text { (República de } \\
\text { Chile, 2005, } \\
\text { Art. 21, }\end{array}$ & $\begin{array}{l}\text { El derecho a desarrollar } \\
\text { cualquiera actividad econó- } \\
\text { mica que no sea contraria a } \\
\text { la moral, al orden público o a } \\
\text { la seguridad nacional, respe- } \\
\text { tando las normas legales que } \\
\text { la regulen. El Estado y sus } \\
\text { organismos podrán desarro- } \\
\text { llar actividades empresariales } \\
\text { o participar en ellas solo si } \\
\text { una ley de quórum calificado } \\
\text { los autoriza. En tal caso, esas } \\
\text { actividades estarán sometidas } \\
\text { a la legislación común apli- } \\
\text { cable a los particulares, sin } \\
\text { perjuicio de las excepciones } \\
\text { que por motivos justificados } \\
\text { establezca la ley, la que debe- } \\
\text { rá ser, asimismo, de quórum } \\
\text { calificado }\end{array}$ & & \\
\hline
\end{tabular}




\section{Conclusiones}

En este artículo se describen los esfuerzos latinoamericanos, representados por la CAN y el MERCOSUR, en la protección de los derechos del consumidor, partiendo de los postulados constitucionales que permiten el adecuado desarrollo de la relación de consumo, por lo que constituyen un primer avance que permitirá, en trabajos futuros, profundizar en los compromisos específicos en el escenario del $e$-commerce.

Los fundamentos normativos encuentran, como punto de partida, la cooperación armónica, que haga posible la integración de los países en la consecución de propósitos comunes, en concordancia con las propuestas de la $\mathrm{CNUDMI}^{3}$, desde una mirada constitucional como marco normativo general, toda vez que existiendo las bases de orden constitucional, el desarrollo legal será viable y posible.

A partir del marco de integración, los países miembros de la CAN y el MERCOSUR disponen fundamentos constitucionales en torno a la libertad de empresa, la iniciativa privada y la libre competencia, postulados que repercuten en el mercado y, en consecuencia, en la protección del consumidor como eslabón débil del mismo.

En torno a la libertad de empresa, la protección a los consumidores se concreta en la posibilidad otorgada a todos los ciudadanos de ejercer una actividad económica libre, repercutiendo en la oferta y demanda en el mercado y en la apertura de opciones al consumidor.

La iniciativa privada, sumada a la libertad de empresa, garantiza el adecuado ejercicio de la actividad económica por parte del empresario, ofreciendo al consumidor seguridad en torno a sus transacciones y los sujetos negociables en el mercado. De esta manera, el consumidor puede contar con la exigencia constitucional y legal que debe cumplir el proveedor y el distribuidor a la hora de participar en la dinámica contractual.

Finalmente, la libertad de competencia, en muchos países, es abiertamente protectora de los derechos del consumidor, pues se encuentran manifestaciones expresas en torno a publicidad engañosa como defensa de los intereses del consumidor. En todo caso, la concepción general permite garantizarle, al

3 "Órgano jurídico de composición universal, dedicado a la reforma de la legislación mercantil a nivel mundial durante más de 40 años. La función de la CNUDMI consiste en modernizar y armonizar las reglas del comercio internacional." (CNUDMI, s. f.) 
consumidor, un mercado dinámico y respetuoso de los avances en innovación y servicios; en este sentido, el consumidor encuentra los bienes y servicios necesarios para la satisfacción de sus necesidades, en un marco de innovación propiciado por la libre y sana competencia.

En este marco económico y jurídico, sin perjuicio de otros factores, las naciones miembros de la CAN y el MERCOSUR contribuyen en la construcción de comunidad latinoamericana, partiendo del compromiso de integración. Escenarios tan agresivos como el mercado de bienes y servicios exigen la colaboración armónica de los Estados, en procura de la defensa de los intereses de sus ciudadanos. 


\section{Referencias}

Área de defensa del consumidor. (s.f.). Derechos y obligaciones del consumidor. Recuperado desde http://consumidor.mef.gub.uy/10263/9/areas/derechos-yobligaciones-de-los-consumidores.html

ASAMBLEA NACIONAL CONSTITUYENTE. (1991). Constitución Política de Colombia.

CAN. (2002). Legislación sobre Comercio Electrónico en los países miembros de la comunidad Andina. Análisis comparativo, recomendaciones para su armonización. Con apoyo de Unión Internacional de Telecomunicaciones. Recuperado de

http://www.itu.int/ITU-D/cyb/publications/archive/Legislacion\%20Comercio\%20 Electronico\%20CAN1.pdf

Centro de Libre Competencia. (s.f.) El derecho de la competencia en Brasil. Recuperado desde http://www.lcuc.cl/documentos_down/mapa/brasil.pdf

CNUDMI. (1996). Ley Modelo sobre Comercio Electrónico. Recuperado de http:// www.uncitral.org/pdf/spanish/texts/electcom/05-89453 S Ebook.pdf

COMISIÓN EUROPEA. (2005). La protección de los consumidores en la Unión Europea.

Constitución Política de Brasil. (1998). Recuperado desde http://pdba.georgetown. edu/Constitutions/Brazil/esp88.html

Constitución Política de Chile. (2010). Recuperado de http://www.oas.org/dil/esp/ constitucion chile.pdf

Constitución Política de Ecuador (2008). Recuperado desde http://www.asambleanacional.gov.ec/documentos/constitucion de bolsillo.pdf

Constitución Política de la Nación de Argentina (1994) recuperado desde http:// www.cepal.org/oig/doc/argentinaconstitucionpolitica.pdf

Constitución Política de Paraguay (1992). Recuperado de http://www.oas.org/juridico/spanish/par_res3.htm

Constitución Política de Perú. (1993). Recuperado desde http://www4.congreso. gob.pe/ntley/Imagenes/Constitu/Cons1993.pdf

Constitución Política de Uruguay. (1997). Recuperado de http://www.rau.edu.uy/ uruguay/const97-1.6.htm 
Constitución Política de Venezuela. (1999). Recuperado desde http://www.oas.org/ dil/esp/Constitucion_Venezuela.pdf

Constitución Política del Estado Plurinacional de Bolivia. (2009). Recuperado desde http://www.harmonywithnatureun.org/content/documents/159Bolivia\%20 Consitucion.pdf

MERCOSUR. (1991). Tratado para la Constitución de un Mercado Común.

MERCOSUR. (2011). Consultoría para análisis de la logística, aspectos aduaneros e impositivos en MERCOSUR y América Latina relacionados con el comercio electrónico y negocios por internet transfronterizos. Recuperado de http://www.MERCOSURdigital.org/img/4.1MD-ComercioElectronico NormativaRC02.1-parte1.pdf

MERCOSUR. (s.f.). Proyecto MERCOSUR Digital. Ecosistemas del comercio electrónico y negocios por internet transfronterizo. Recuperado de http://www.MERCOSURdigital.org/img/1MD-ComercioElectronico EcosistemaRC02.2.pdf

OCDE. (2003). Directrices para la protección de los consumidores de prácticas comerciales fraudulentas y engañosas. Recuperado de http://www.oecd.org/ sti/consumer/34012151.pdf

REMOLINA Angarita, N. (2006). Aspectos legales del comercio electrónico, la contratación y la empresa electrónica. Revista de Derecho Comunicaciones y Nuevas Tecnologias, 323 - 370. Recuperado de http://derechoytics.uniandes.edu.co/components/com_revista/archivos/derechoytics/ytics77.pdf

REMOLINA Angarita, N. (2012). La protección del consumidor en el contexto del comercio electrónico Revista de Derecho Comunicaciones y Nuevas Tecnologías, 2 - 19. Recuperado de http://derechoytics.uniandes.edu.co/components/com_revista/archivos/derechoytics/ytics115.pdf

REMOLINA Angarita, N. (2011). Ley 1480 por medio de la cual se expide el Estatuto del Consumidor.

UE. (2005). La protección de los consumidores en la Unión Europea: Diez principios básicos. Recuperado de http://ec.europa.eu/consumers/cons info/10principles/es.pdf

UNCITRAL, Ley modelo de Comercio Electrónico. 